\title{
LOOKING AT THE IMMIGRANTS' FACES. THE STUDY OF AUDIENCE'S EMOTIONS AND ATTITUDE TOWARD IMMIGRANTS THROUGH A DOCUMENTARY FILM
}

\author{
Paciello Marinella \\ Faculty of Psychology \\ Uninettuno Telematic International University \\ m.paciello@uninettunouniversity.net \\ Cerniglia Luca \\ Faculty of Psychology \\ Uninettuno Telematic International University \\ D'Errico Francesca \\ Department of Philosophy \\ Communication and Visual Arts \\ University of Roma Tre, Rome, Italy \\ Cersosimo Mariangela \\ Faculty of Psychology \\ Uninettuno Telematic International University \\ Arrigo Pedon \\ Faculty of Psychology \\ Uninettuno Telematic International University
}

Fecha de Recepción: 8 Abril 2019

Fecha de Admisión: 30 Abril 2019

\begin{abstract}
In line with the refugee agency recommendations (UNHCR, 2010) the present research recruited citizens in the general population with the aim of understanding whether positive media messages may foster acceptance towards refugee immigrants. The study has specifically considered the case of unaccompanied refugee minors verifying if and how specific affective and cognitive dimensions implicated in individual moral functioning were related to empathic or hostile emotions experienced while watching a documentary realized by refugee minors in a hosting centre in Italy. In addition, the relationship between different emotional responses and attitudes toward immigrations were examined. Fifty student were invited to complete pre-assessment questionnaire containing measures on empathic tendencies (e.g. perspective taking, Davis, 1990) personal values (self-enhancement values, Schwartz, 1992) and moral regulation (e.g. moral efficacy; Bandura, 1991). Then, voluntary participants were invited to watch the documentary film produced in the a European Project.
\end{abstract}


After the presentation of the film, the students have to indicate their current emotional states and attitude toward immigration as spectators. Overall, the results showed that self-transcendence values, empathic concern and moral self-efficacy were positively related to sympathy, and negatively related to hostile emotions. Differently, moral disengagement was positively related to negative affect. Moreover, the presence of empathic affect during the film was associated with positive attitudes toward immigrations; on the contrary, the presence of hostile emotions was strongly related to negative attitudes toward hosting. Overall, results suggest the importance of considering citizens' moral sensitivity, motivation and moral regulative capabilities together audio-visual contents to better understand people's emotions in relation to immigration and hosting.

Keywords: morality; personality; immigration; documentary film; emotions

\section{INTRODUCTION}

Movie production represents one of the most creative strategies to enhance the understanding of the human condition and promote awareness of several critical issues (Igartua, 2010; MoyerGusè, 2008). Indeed, in very different fields film have been used within an educational framework for highlighting and reflecting on human and social problems (Blasco, Mônaco, De Benedetto, Moreto, and Levites, 2010), as in the case of documentary films. A way to capture the audience attention is to elicit emotions (Lehnen, 2016) - that the moviemaker ideally intends to elicit - able to activate specific social and cognitive process: "emotion is the glue that keeps the movie audience in their seats" (Carroll, 2010, p.7). When ethical topics are presented, as in the case of topic of immigration, both positive and negative emotions could be experienced by the audience: some spectator can empathize with the main character (i.e., immigrants), others can feel annoyed. To understand the different emotional reactions, and, subsequently, the attitudes toward some ethical issues, the interaction between documentary and moral individual characteristics need to be considered. In this case of moral emotions, both positive (i.e. empathic feelings) and negative (i.e. hostile emotions) could be strictly related to pre-existent individual structures and moral processes activating during watching the film. Indeed, emotions represent forms of value judgments when facing ethical topics, and individual characteristics, such as moral sensitivity, motivations and processes, can direct the perception of what is right or wrong to do: in the case of immigration, helping or not out-group people in a state of need. In other terms, the individual moral dimensions can pre-focus attention and make the difference with respect to opposite feelings that audience can experience.

Consistently with these premises, the present study aims to investigate the possible effects of a creative media product, that is a documentary movie developed within a European Project aimed, in line with the refugee agency (UNHCR, 2010), to promote moral standard and immigrants' rights across nations. In the last years, the phenomenon of migration has been increasingly perceived by citizens as one of the most threatening social risks to local identities and security (Esses et al. 2013), and it could be important to understand if and how creative products realized with ethical purpose can mediate different emotions and attitudes toward immigrants.

First, in line with the literature on moral emotion (Haidt, 2003), both positive (i.e. empathic feelings) and negative (i.e. hostile emotion) were taken into account to understand moral and, more specifically, prosocial orientation. Indeed, moral emotions are associated with different moral cognitions and behaviour. Seminal psychological studies focused on emotional dimensions had repeatedly confirmed the role of other empathic emotions in promoting prosocial behaviors (Hoffmann, 2008) and, on the other side, the role of hostile emotions in promoting harmful behaviors (Anderson and Bushman, 2002). Also in the case of immigration, studies have attested the crucial role of otheroriented emotions, such as empathy (Sirin, 2016), in promoting pro-civic rights and the role of hostile emotions in hindering hosting and foster discrimination (D’Errico \& Paciello, 2018). 
With respect to individual dimensions predisposing different affective reactions to documentary film - concerning the specific case of immigration- empathic dimensions, personal values and moral regulative processes were examined. In line with previous literature on individual differences and moral behavior (Myyrya, Juujärvi, and Pesso, 2010; Pohling et al, 2010) these dimensions can capture different aspects of individual moral functioning. Empathic dimensions can reflect the individual's moral sensitivity to moral topic related to care/harm domains (Graham et al., 2011). Actually, empathy promotes a mode of reasoning oriented to improve others' conditions (Batson, 2011). Several research on prosocial motives have documented that when people feel true empathy, they perform helping behaviors to reduce others' negative feelings, even if their own personal interests are compromised (Paciello et al. 2013). In the case of immigration the social and cultural distances can hinder empathy and helping behaviors toward immigrant (López Rodríguez et al., 2017), the severity of the situation can emotionally distress a potential helper (Dovidio et al., 1991), and the perception of possible threats to in-group interest can be associated to hostile emotions (D'Errico \& Paciello, 2018; 2019). In other terms, stronger individual empathic tendencies could be required in this high-cost helping scenario.

Personal values refer instead to moral motivations of helping behavior. Values transcend specific situations and serve as general criteria to select and evaluate one's own decisions and actions. With respect to care domain, literature had suggested that self-transcendence values direct attention to others' needs and promote prosocial behavior, whereas self-enhancement values legitimize self-serving behaviors and allows individuals to avoid involvement with others in need (Schwartz, 2010). In the specific case of immigration, previous findings have confirmed the role of self-transcendence and self-enhancement in promoting or jeopardizing inclusive and supportive behaviour toward immigrants; moreover, conservation values (e.g. security) seem to be inversely related to the attitude towards hosting immigrants (Sagiv and Schwartz, 1995).

Nevertheless, since the presence of values and empathy doesn't guarantee a consistent moral orientation and behavior, regulative moral processes have also considered. Specifically, in this study we refer to moral agency theory (Bandura, 1991). Within this theoretical framework, people are considered as active agents who pursue their goals in accordance with moral values. In particular, the moral self-regulative processes could allow aligning moral though and moral conduct. These capabilities can take a proactive or an inhibitive form: the proactive self-regulative capabilities fosters moral action by adjusting it according to moral standards and by anticipating positive evaluativereactions such as pride and satisfaction; inhibitive capabilities, instead, impedes engagement in immoral behaviors by anticipating self-evaluative reactions, such as guilt and shame that may result from the negative effects of their unethical action (Bandura, 1991). In the present study, we consider these capabilities in terms of moral self-efficacy in line with Bandura theory and consistently with a large literature attesting the role of perceived self-efficacy beliefs on foster prosocial behavior (e.g., Caprara \& Steca, 2005). Moreover, considering that moral self-regulation process does not always work in a constant and continuous way (Bandura, 1991; 2015), we examine moral disengagement mechanisms through which self-sanctions can be deactivated and affective self-evaluative reactions are avoided, permitting different types of unethical conduct, such as omission (Paciello et al. 2013). Moral disengagement could be considered as a cognitive distortion by which individuals may regard their unethical behavior and its negative consequences in a socially and morally favourable way, not contradicting their personal values and social norms. In the case of immigration, recent literature has attested that this mechanism foster racism (Faulkner \& Bliuc, 2016) and hinder hosting immigrants, in association with hostile emotions (D’Errico e Paciello, 2018). 


\section{AIMS OF THE PRESENT STUDY}

Considering the case of unaccompanied refugee minors, that often pay the high costs of prejudices, the research intends to examine the impact of positive media messages considering the individual dimensions that could support public attitude towards accepting minor refugee immigrants. The main purpose of the research is to assess the emotional impact of the documentary and audiovisual products produced within the project as a tool of 'vicarious contact' (Dovidio et al, 2011) to promote positive attitude toward immigrants. Specifically, the following strategic objectives have been defined:

- to examine the opposite emotional reactions (i.e. empathic response and hostile emotions) and attitude toward immigration (i.e. favourable and adverse ones) of viewers to the documentary film produced.

- to examine personal profiles associated with opposite feelings and attitudes, in terms of moral sensitivity (affective and cognitive empathy), motivation (personal values) and moral regulative processes (moral self efficacy and moral disengagement).

\section{METHOD}

\section{Sample and Procedure}

Fifty university students attending psychology course were invited to watch the documentary film realized in European Project 'Re-Future' (https://www.re-future.eu/en/default.aspx). The film was realized by collecting several videos recorded by Unaccompanied Refugee Minors in a hosting centre in Italy. During a training session on video literacy, refugee minors had used their smartphone cameras to describe their story from their own point of view. The documentary had the goal to promote vicarious contact (Dovidio et al., 2011) in the potential audience by representing refugees in their daily activities.

Before the start of the study, students were invited on the class web-forum in which a researcher explained the study procedures and was available for dispelling any possible doubts. Students, that have participated to the research (60\% of invited students; $79 \%$ females), gave their written informed consent.

After the adhesion, the students watched the documentary film (about 1 hour) by means a connecting tool within Uninettuno platform. After the documentary film, participants completed an online survey to indicate their level of empathy experienced during the movie, their level of hostile feelings (e.g. anger, contempt) as well as their positive ( 5 items) and negative attitude (4 item) toward immigration by using a 5 point Likert scale.

At the end of the data collection, the students received a general feedback and were invited to discuss on the documentary film in an online interactive class. The participation to this study was rewarded with two formative credits. The mean age of participants was 42 years ( $s d=14$ years).

\section{Pre-assessment measure}

Before the documentary film, participants completed an online pre-assessment questionnaire measuring the following personality dimensions.

Empathic concern and perspective taking. The Interpersonal Reactivity Index, IRI (Davis, 1983) is a self-reported questionnaire that assesses perceived individual differences in the tendency to be empathetic. In this study we used the Italian version of IRI (Ingoglia, Lo Coco, Albiero, 2016). IRI consists of 28 Likert-type items on a response scale with five alternatives ranging from 1 (Does not describe me well) to 5 (Describes me very well). In this study, we use two subscales: perspective taking and empathic concern. The subscale perspective taking evaluates the propensity to adopt the 
views of others in the life of every day(cognitive empathy). The subscale empathic concern investigates the tendency to experience feelings of compassion and concern for people having negative (affective empathy).

Personal values. These were assessed by Portrait Values Questionnaire (PVQ; Schwartz, 1992), which includes 40 items, each portraying a person (his/her aspirations, goals and important aspects of his/her life). Participants were asked to rate how similar to the described person they felt themselves to be using a 6-point Likert scale (from "Very similar" to "Very dissimilar"). For the present study we took into account the four macro-dimension of the scale: self-transcendence, selfenhancement, conservation, and openness to change.

Moral self-efficacy and disengagement. Moral self efficacy was assessed by using an ad hoc scale including 7 item on the perceived capability to resist to act unethical behavior (inhibitive way) and to act ethically (proactive way) in situation in which is more convenient/easy to choose bad way or more difficult to stay anchored to one's own values. Response scale range from complete unable (1) to totally able. Moral disengagement was measured using the scale developed by Bandura and colleagues (Bandura et al., 2001). The 32-item tool assesses the mechanisms by which moral selfsanctioning can be disengaged from unmoral behavior. For each item, participants rated on a 5-point Likert type scale (from "Do not agree at all" to "Completely agree") their degree of acceptance of moral exoneration for described behaviour.

\section{RESULTS}

\section{Affective Reactions and Attitude toward Immigration}

As shown in Figure 1, empathic and hostile reactions showed different distributions: higher levels of positive emotion (mean $=3.9, \mathrm{sd}=1.13$ ) and lower levels of negative ones (mean=1.6, $\mathrm{sd}=$ .71). Parallel trend distribution follows positive (mean $=3,8, \mathrm{sd}=.81$ ) and negative attitude (mean = $1.6, \mathrm{sd}=.74$ ) toward hosting immigration (Figure 1). No gender differences emerged from T test analysis.

Figure 1. Emotional reaction and attitude distributions
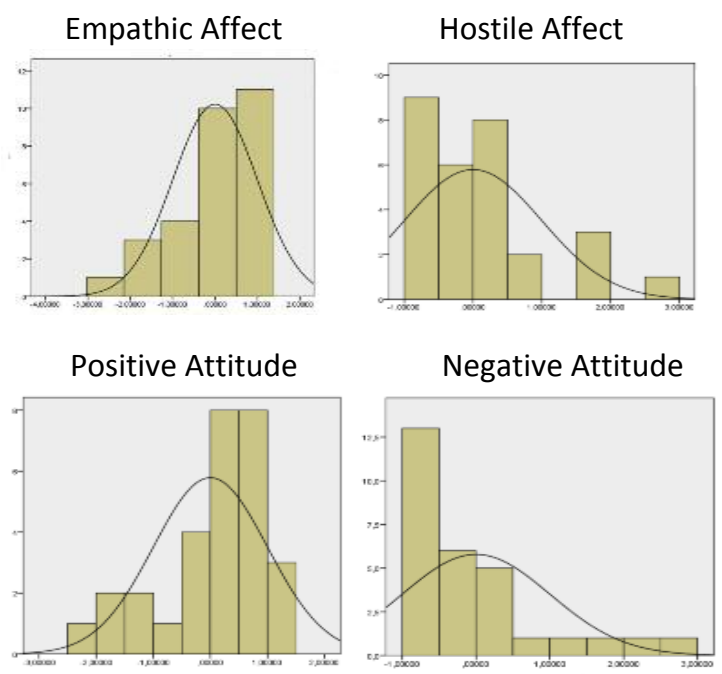
With regard to the possible relations among emotions and attitudes, correlational analyses attested that empathic response was negatively associated with negative attitude toward hosting ( $r=$ -.42), and positively associated with positive attitude $(r=.50)$. On the contrary, hostile emotions were only positively associated with negative attitudes $(r=.43)$.

\section{Correlations among personality variables, emotional reactions and attitudes toward hosting}

As shown in Table 1 and 2, personality variables were strongly associated with reactions to documentary film and audience attitudes. In particular, empathic reactions were predicted by individual tendencies in cognitive and affective empathy, self-transcendence and moral self-efficacy. Moreover, moral disengagement was negative associated with empathic reaction to documentary film. Hostile emotions were instead negatively associated with empathic concern and self-transcendence, and are positively associated with moral disengagement.

Table 1. Association between personality dimensions and emotional reactions

\begin{tabular}{lcc}
\hline & \multicolumn{2}{c}{ Affect } \\
\cline { 2 - 3 } Empathy & $.63^{* *}$ & $-.67^{* *}$ \\
Pers T & $.55^{*}$ & -.46 \\
Self Tr & $.51^{*}$ & $-.57^{*}$ \\
Self En & -.36 & -.05 \\
Cons & .42 & .08 \\
Open & .23 & -.28 \\
MD & $-.59^{*}$ & .32 \\
Moral Eff & $.50^{*}$ & $-.59^{*}$ \\
\hline
\end{tabular}

Note : empathy = empathic concern; Pers = perspective taking; Moral Eff= moral self-efficacy; MD $=$ moral disengagement; $\operatorname{Self} \mathrm{Tr}=$ self transcendence; Self En = self enhancement; Cons $=$ consenservation; Open $=$ openness to change

With regards to attitude toward hosting immigrants, correlational analyses attested that positive attitude was positively associated with perspective taking, self-transcendence and conservation; whereas it was negatively associated with moral disengagement. Negative attitude toward immigration was negatively associated with empathic concern, self-transcendence and openness to change. 
Table 2. Association between personality dimensions and attitude toward hosting immigrants

\begin{tabular}{lcc}
\hline & \multicolumn{2}{c}{ Attitude } \\
\cline { 2 - 3 } Empathy & Positive & Negative \\
Pers T & .53 & $-.60^{*}$ \\
Self Tr & $.53^{*}$ & -.46 \\
Self En & -.14 & $-.64^{* *}$ \\
Cons & $.50^{*}$ & -.37 \\
Open & .39 & -.15 \\
MD & $-.52^{*}$ & .40 \\
Moral Eff & .43 & -.43 \\
\hline
\end{tabular}

Note: empathy = empathic concern; Pers = perspective taking; Moral Eff= moral self-efficacy; MD $=$ moral disengagement; Self $\operatorname{Tr}=$ self transcendence; Self En $=$ self enhancement; Cons = consenservation; Open $=$ openness to change

\section{Emotional reactions and attitude toward hosting: Spectator's profile}

To exam the difference between spectators experiencing negative and positive emotions on personality dimensions, a $\mathrm{T}$ test was performed. All personality variables were considered as the depend variables, while, as the independent variable we considered the sample was divided in two groups: one group - empathic group - with high levels of empathic reaction ( $>3)$ and low levels of hostile emotions $(<3)$; and one group - hostile group - with opposite emotional reactions, i.e. low levels of empathic reactions $(<3)$ and high levels of hostile reactions $(>3)$. Results attested that "hostile group" ( $30 \%)$ was characterized by lowest levels of empathic concerns ( $t=3.31 ; p=.005)$ and perspective taking $(t=2.96 ; p=.01)$, self-transcendence values $(t=2.97 ; p=.009)$ and moral selfefficacy $(t=5.11 ; p=.0001)$. Moreover this group showed highest level of moral disengagement $(t=-$ $3.64 ; p=.002$ ) (figure 2).

Figure 2. hostile vs empathic spectators - profile

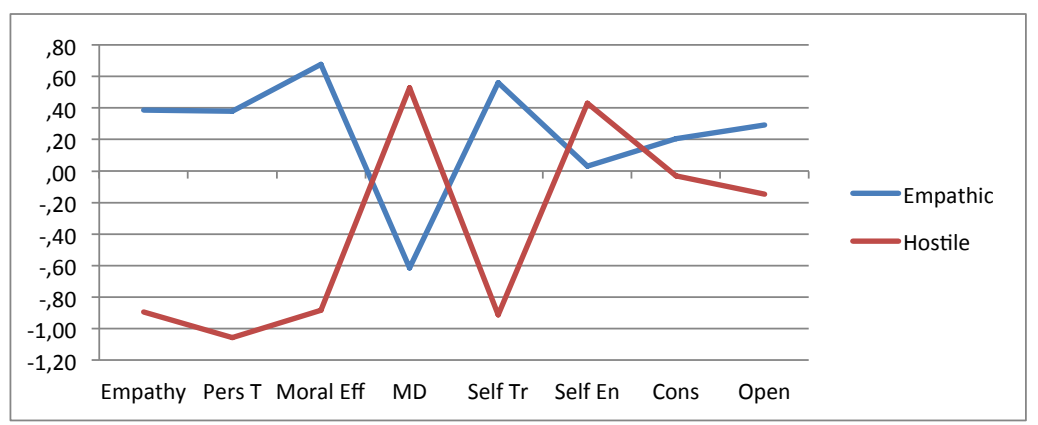

Note $:$ empathy = empathic concern; Pers = perspective taking; Moral Eff= moral self-efficacy; MD $=$ moral disengagement; Self $\mathrm{Tr}=$ self transcendence; Self En $=$ self enhancement; Cons $=$ consenservation; Open = openness to change 
Similarly, attitudes has been examined. A T test was performed by using all personality variable as dependent variables and the group as the independent variable (favourable vs. adverse spectator). Results attested that "adverse group" ( $25 \%$ ) was only characterized by lowest levels of perspective taking ( $t=3.09 ; p=.007)$, and moral self-efficacy $(t=3.37 ; p=.005)$.

Figure 3. favourable vs. adverse attitude toward immigrants -profile

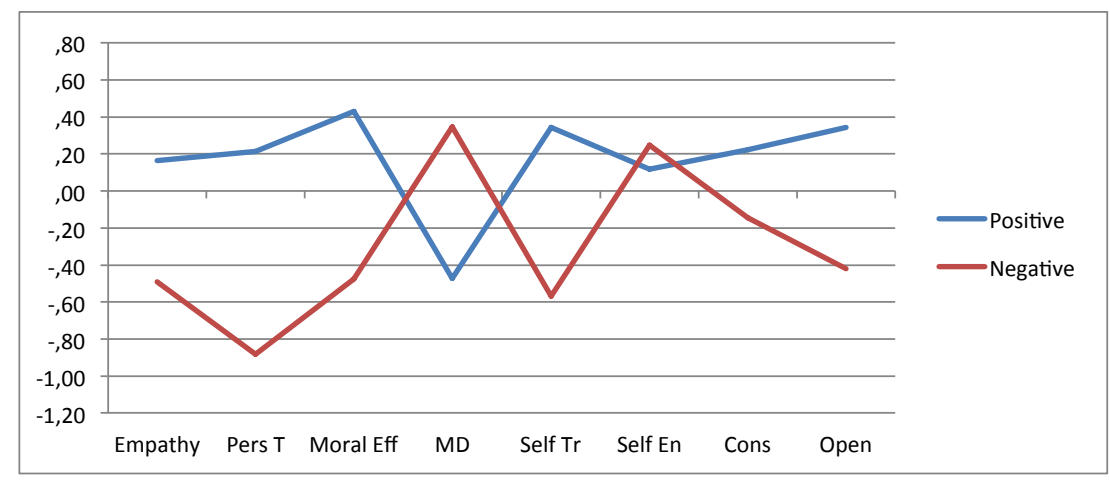

Note: empathy = empathic concern; Pers = perspective taking; Moral Eff= moral self-efficacy; MD

$=$ moral disengagement; Self $\mathrm{Tr}=$ self transcendence; Self En = self enhancement; Cons $=$

consenservation; Open $=$ openness to change

\section{DISCUSSION}

In line with previous studies focused on fictional movies (Igartua, 2010; Moyer-Gusè, 2008), the present study showed how even a documentary film, which described refugees' daily activities in the hosting centre, aroused feelings of empathy that were associated with a favorable attitude towards acceptance, promoting a sort of vicarious contact (Dovidio et al., 2011). In particular, the results confirmed the importance of empathy and its close association with the attitude towards hosting immigrants. Certainly, we must consider that it is very likely that these creative products can be chosen by people who already have a greater tendency to empathize with this issue. In fact, the majority of the spectators who feel empathy have basically moral characteristics that favor such emotions, or rather they are more morally sensitive, more motivated towards help and care and feel themselves morally effective.

As to the attitudes, which represent more stable dimensions, however, the individual cognitive dimensions associated with the sphere of behavioral regulation made the difference since they are able to represent the other's mental state and parallel to align their conduct with the moral principles they support.

It is interesting to note that in this study, unlike in other studies, conservatism plays an opposite role. The values of tradition, family and security together with those of universalism are individual aspects that motivate help to immigrants. Conservatism must therefore be understood considering the type of value configuration in which it is inserted, that can be featured by benevolence, tradition and security and then be linked to Catholics' values (Schwartz \& Huismans, 1995).

With regard to hostile reactions in line with previous studies (D'Errico \& Paciello, 2018; 2019), our results confirmed the close association with individuals' difficulties in understanding the inter- 
nal state of the other and also in morally regulating themselves. Even with regard to the hostile attitude the values together with empathy play an important role: in particular it is interesting to note that not only universalism but also openness to change contributes to inhibiting a hostile attitude.

Finally our study represented a first quasi-experimental study that deepened the socio-cognitive features of the audience at the end of a documentary narrating immigrants' real daily activities (from immigrants' perspective). In our knowledge in fact, previous studies in the filed of media persuasion research had mainly explored the immigrants' characteristics, for example in terms of similarity (Igartua, 2010; Moyer-Gusè, 2008) in affecting outgroup members' attitudes. In our view studying audience' psychological features allow us to define and test, also in future studies, 'persuasive narratives' tailored to promote positive attitudes toward immigrants' hosting.

The results of this study must be considered in view of some limitations. First, the recruited subjects belonged to a homogeneus population of psychology students. It is quite clear that this can be a highly specific population, especially when assessing variable as empathy and moral behavior. This limits wide replicability of our study. Second, the documentary film consists of a cutted version, whereas it could have been interesting to assess spectators reactions to uncutted/raw material recorded by the refugees. Third, we did not tested the possible persistent effect of the documentary film on feeling and attitudes of spectators towards immigration and hosting.

\section{Acknowledgments}

This study was supported by Project 'Re-Future' - Creative Europe - Sub-programme Culture, Action: Support for Refugee Integration Projects

\section{REFERENCES}

Anderson, C.A., \& Bushman, B. J. (2002). Human aggression. Annual review of psychology, 53.

Bandura, A., Caprara, G.V., Barbaranelli, C., Pastorelli, C., \& Regalia, C. (2001). Sociocognitive selfregulatory mechanisms governing transgressive behavior. Journal of Personality and Social Psychology, 80(1), 125-135.

Bandura, A. (1991). Social cognitive theory of moral thought and action. In W. M. Kurtines \& E. J. L. Gewirtz (Eds.), Handbook of moral behavior development (Vol. I) (pp. 45-103). Hillsdale, NJ: Erlbaum.

Batson, Daniel (2011). Altruism in humans. New York: Oxford University Press.

Blasco, P. G., Mônaco, C. F., De Benedetto, M. A. C., Moreto, G., \& Levites, M. R. (2010). Teaching through movies in a multicultural scenario: overcoming cultural barriers through emotions and reflection. Fam Med, 42(1), 22-4.

Caprara, G.V., \& Steca, P. (2005). Self-efficacy beliefs as determinants of prosocial behavior conducive to life satisfaction across ages. Journal of Social and Clinical Psychology, 24(2), 191217.

Carroll, N. (2010). Movies, the moral emotions, and sympathy. Midwest Studies in Philosophy, 34(1), 1-19.

D’Errico, F., \& Paciello, M. (2018). Online moral disengagement and hostile emotions in discussions on hosting immigrants. Internet Research, 28(5), 1313-1335.

D'Errico, F., \& Paciello, M. (2019). Online moral struggles in hosting immigrant's discourses: the underlying role of expressed anger and socio-cognitive processes. Journal of language aggression and conflict, $7(2)$

Davis $\mathrm{M} \mathrm{H}$. (1983) Measuring individual differences in empathy: evidence for a multidimensional approach. Journal of Personality and Social Psychology, 44 (1) 113-126. 
Dovidio, J.F., Piliavin, J.A., Gaertner, S.L., Schroeder, D.A., \& Clark III, R.D. (1991). The arousal: Cost-reward model and the process of intervention: A review of the evidence. In M. S. Clark (Ed.), Review of personality and social psychology, Vol. 12. Prosocial behavior (pp. 86-118). Thousand Oaks, CA, US: Sage Publications, Inc.

Dovidio, J. F., Eller, A., \& Hewstone, M. (2011). Improving intergroup relations through direct, extended and other forms of indirect contact. Group processes \& intergroup relations, 14(2), 147-160.

Faulkner, N., \& Bliuc, A. M. (2016). 'It's okay to be racist': moral disengagement in online discussions of racist incidents in Australia. Ethnic and Racial Studies, 39(14), 2545-2563

Graham, J., Nosek, B. A., Haidt, J., Iyer, R., Koleva, S. and Ditto, P. H. (2011), "Mapping the moral domain", Journal of Personality and Social Psychology, Vol. 101 No 2, pp. 366-385.

Haidt, J. (2003). The moral emotions. Handbook of affective sciences, 11(2003), 852-870.

Hoffman, M. L. (2008). Empathy and prosocial behavior. Handbook of emotions, 3, 440-455.

Igartua, J. (2010). Identification with characters and narrative persuasion through fictional feature films. Communications, 35(4), pp. 347-373.

Ingoglia S, Lo Coco A, Albiero P. (2016). Development of a Brief Form of the Interpersonal Reactivity Index (B-IRI). Journal of Personality Assessment, 98, 5, 461-71

Esses, V.M., Medianu, S. and Lawson, A.S. (2013). Uncertainty, threat, and the role of the media in promoting the dehumanization of immigrants and refugees. Journal of Social Issues 69(3): 518536.

Lehnen, C. (2016). Exploring Narratives' Powers of Emotional Persuasion through Character Involvement: A Working Heuristic. Journal of Literary Theory, 10(2), pp. 247-270.

Moyer-Gusé, E. (2008). Toward a theory of entertainment persuasion: Explaining the persuasive effects of entertainment-education messages. Communication theory, 18(3), 407-425.

Myyrya, L., Juujärvi, S., \& Pesso, K. (2010). Empathy, perspective taking and personal values as predictors of moral schemas. Journal of Moral Education, 39(2), 213-233.

Paciello, M., Fida, R., Cerniglia, L., Tramontano, C., and Cole, E. (2013). High cost helping scenario: The role of empathy, prosocial reasoning and moral disengagement on helping behavior. Personality and Individual Differences 55(1): 3-7.

Pohling, R., Bzdok, D., Eigenstetter, M., Stumpf, S., \& Strobel, A. (2016). What is ethical competence? The role of empathy, personal values, and the five-factor model of personality in ethical decision-making. Journal of Business Ethics, 137(3), 449-474.

Sagiv, L., \& Schwartz, S. H. (1995). Value priorities and readiness for out-group social contact. Journal of personality and social psychology, 69(3), 437.

Schwartz, S. H. (1992). Universals in the content and structure of values: Theoretical advances and empirical tests in 20 countries. In M. Zanna (Ed.), Advances in experimental social psychology (Vol. 25 pp. 1-65). New York, NY: Academic Press.

Schwartz, S. H., \& Huismans, S. (1995). Value priorities and religiosity in four Western religions. Social Psychology Quarterly, 58(2), pp. 88-107

Sirin, C. V., Villalobos, J. D., \& Valentino, N. A. (2016). Group Empathy Theory: The effect of group empathy on US intergroup attitudes and behavior in the context of immigration threats. The Journal of Politics, 78(3), 893-908. 